\title{
Can Soap be a Sustainable alternative to Petroleum based Thermal Insulation?
}

\author{
Lee Read, Yusuf Arayici \\ School of the Built Environment, \\ College of Art and Technology, \\ Salford University, \\ l.read@edu.salford.ac.uk, y.arayici@salford.ac.uk
}

\begin{abstract}
Thermal insulation is important to achieve energy efficiency in a buildings' lifespan while maintaining comfort. Traditionally, the majority of insulation in buildings is manmade petroleum based products with limited or no-end life usage. However, from an environmental and economic sustainability perspective, they are not sustainable as natural resources are finite and in danger of run-out. Furthermore, they are also highly influenced by the increasing price and the ongoing scarcity of fossil fuel oils.
\end{abstract}

This paper introduces soap based insulation from recycled materials as a sustainable alternative to petroleum counterparts. The methodology is lab based experimentation and iterative tests. The phased based research process for the incremental development of the soap based thermal insulation is explained.

Findings reveal that soap based insulation can be one possible way forward in the quest for natural and sustainable thermal insulation from recycled products to preserve and conserve the sustainable environment.

Thus, the paper provides a unique environmentally friendly approach as an alternative to those existing petroleum counterparts for thermal insulation in buildings

Keywords: Soap insulation, petroleum insulation, sustainability, recycled products, thermal insulation 


\section{Introduction}

Thermal insulation is critical to achieve high energy efficiency throughout a building's lifespan by maintaining comfort within the building space (Powell \& Mathews, 1987). Heat transfer only occurs when there is a temperature difference between a warm zone and a cold zone (Bejan, 2004). In order to stop this heat leaching, a barrier must be installed, manufactured from a material with relatively low thermal conductivity (ICAEN, 2004).

This barrier will usually take the form of thermal insulation, and as with most thermal insulations, this works on the trapped air principle (pockets of air within the insulation body). The arrangement of the molecules within these air pockets is such to utilize air as the insulator. In relative terms, the molecules in air are spaced quite far apart. This makes heat transfer via the molecules difficult. This is because air is a very low density material. The sparsity of atoms per unit volume means that there are few heat transfer type collisions (vibrations). If the air is trapped (and therefore motionless) it cannot transfer heat to another location.

From a building physics point of view, this is the principle reason why cavity wall construction (trapped air between two brick skins), was adopted in buildings throughout the UK from the 1950's onwards. The air insulator frustrates the heat transfer mechanism of all three heat transfer mechanisms. These are:

- Conduction: this is the transfer of energy between objects that are in direct physical contact. Denser substances are better conductors.

- Convection: this is the transfer of energy between an object and its environment, due to fluid motion, in this example - gas. It cannot take place in solids, since neither bulk current flows nor significant diffusion can take place in solids.

- Radiation: this is the transfer of energy in the form of rays, waves or particles, to or from a body by means of the emission or absorption of electromagnetic radiation.

The soap based insulation products can be used in walls, floors and roofs to maintain a gradient of temperature by reflecting heat as opposed to allowing its absorption and escape. 
Traditional practice in thermal insulations is limited to the man-made petroleum based products, with limited or no end of life usage (Ryan, 2011). This research targets sustainability measures simply because the earth's resources are finite and as such are in danger of eventually running out (MacKay, 2009). It targets waste because wastage directly contributes to resources running out and it targets the viability of alternative and recycled plastics because of the ever increasing price and the ongoing scarcity of fossil fuel oils which are required in the manufacturing of petroleum based insulations.

Soap insulation, derived from fats, oils and wood ash residue is natural (Grosso, 2002) and can be a sustainable alternative. Blended oils and lye can create a crude soap mixture that can be aerated and surrounded in recycled plastic to create thermal insulation. Trapped bubble aeration within the insulation body will give the soap insulation its thermal properties (DeGunther, 2010).

This paper will examine if soap can be produced from recycled materials for an environmentally friendly thermal insulation. For that that purpose, this paper explains the experimental research process in which various alternatives are tested in order to propose the best possible specification for soap production from recycled materials and then discusses it in comparison with petroleum counterparts to define the way forward for creating environmentally friendly thermal insulation.

\section{Background to Thermal Insulation}

Thermal insulation is a barrier to limit heat transfer. In theory, to minimize the amount of heat transferred between the inside and outside walls of a building, we must make the wall a poor heat conductor by choosing a building material or barrier with low thermal conductivity. Most heat transfer is via conduction, involving a transfer of energy within a material without any motion of the material as a whole. The rate of heat transfer through the wall of a building depends upon the temperature gradient and the thermal conductivity of the wall material. The rate of conduction for heat transfer (according to Fourier's Law) is shown in figure 1, 


$$
\begin{aligned}
& \frac{Q}{t}=\frac{\kappa A\left(T_{\text {hot }}-T_{\text {cold }}\right)}{d} \\
& \frac{Q}{\mathrm{Q}}=\text { heat transferred in time }=t \\
& \kappa=\text { thermal conductivity of the barrier } \\
& A=\text { area } \\
& T=\text { temperature } \\
& d=\text { thickness of barrier }
\end{aligned}
$$

Figure 1: heat transfer calculation (Adapted from Nave, 2010)

Thermal insulation is a barrier with low thermal conductivity. Adding this barrier to the outside, inside or within the cavity of a buildings' wall will frustrate the leaching of heat. Thermal insulation also provides a heat-leaching barrier to floors and roofs.

Historically, modern insulations were introduced into UK domestic lofts in the 1960's, usually in the form of fibreglass rolls (Goodall, 2012). Polystyrene and fibreglass cavity wall insulation were introduced into dwellings during the 1970's (Long, 2006). This older insulation was often manufactured from formaldehyde and other toxic substances that are released into the atmosphere as the insulation degrades (Kirk, 1997). This can create health problems where human contact and exposure meet. As technology evolved, improvements were made to the thermal insulations. These improved insulations are still in use today.

There are four main types of foamed plastic wall, floor and roof insulations that are commonly used within the construction industry. Alongside these, multilayered reflective foil and fibreglass insulations are also used, but to a lesser extent (Celotex, 2010). Green, sustainable insulations are becoming more popular, but occupy a very small niche in the market generally. The six main insulation types are as follows:

1. Extruded polystyrene (XPS) This insulation is manufactured by liquifying polystyrene pellets with various other ingredients. Gas bubbles are then formed by introducing a blowing agent into the mix. As with most polystyrenes, the insulation works on the trapped bubble principle, but utilising hydrochlorofluorocarbon (HCFC) 
bubbles containing compounds of chlorine, fluorine, carbon and hydrogen as opposed to air. The resulting liquid foam is then cooled to produce closed-cell foam that is both rigid and waterproof.

2. Extruded polyethylene (XPE) is manufactured by blending polyethylene pellets and various other chemicals. An injected blowing agent is added to the mixture to cause an HCFC foaming reaction. When cooled, flexible plastic closed-cell foam is created.

3. Expanded polystyrene (EPS) Expanded polystyrene is made from pre expanded styrene beads (enlarged with pentane). Heat and pressure is applied to enable the beads to stick together. This insulation is mostly used for floor insulation as it is difficult to achieve the correct wall and roof $U$ values (overall heat transfer coefficient) with the thicknesses manufactured (Celotex, 2012).

4. Polyurethane (PUR) and polyisocyanurate (PIR) are created by blowing hydrocarbon pentane gas into a urethane mixture. This produces a free frothy insulation that when dry creates an insulation of high thermal efficiency. PUR and PIR insulations also work on the trapped bubble principle and are very effective at not just limiting heat transfer, but at stopping it. A large proportion of these types of insulation also have an aluminium radiant heat reflective covering that allows the product to work at a superior level to polystyrenes. PUR and PIR insulations are by far the most popular insulations that are used for wall, floor and roof insulations within the UK (Kutz, 2011).

5. Fibreglass insulation is what the name suggests, fibres of glass. Sand and recycled glass are heated to $1,450^{\circ} \mathrm{C}$ and fused together. The resulting glass mixture is forced through a fine mesh to convert it into fibres. A liquid binder is added to glue the fibres together. Fibreglass insulation remains popular as both loft insulation and cavity wall insulation. It is very effective at slowing down the heat transfer mechanism, by trapping air within its layers and around its fibres.

6. Multifoil insulation is comprised of reinforced top and bottom sheets of foil, with multi-layered reflective sheets between. These sheets are separated by foam, wool or wadding and then sown together to create a thin insulation blanket. The insulation is typically $10 \mathrm{~mm}$ to $30 \mathrm{~mm}$ thick. This type of insulation works on the layered air 
trapping principle as opposed to the trapped bubble rule of action.

There are other insulations on the market that can be classed as more environmentally friendly than the others previously listed. The list of these includes, but is not limited to:

7. Sheepswool insulation is both natural and environmentally friendly. It is nonhazardous to health, allergy free, comparable to rockwool and does not support combustion. Sheepwool insulation is breathable and as such it will absorb moisture in wintertime to help keep a property warm and release moisture in the summertime to help keep the property cool (Zach et al, 2012). Thicknesses generally start at $100 \mathrm{~mm}$. Sheepswool, as with Hemp and similar insulation products work by trapping air within their layers.

8. Hemp insulation has much the same thermal conductivity as sheep's wool and fibreglass. Hemp insulation also absorbs moisture helping it to breathe. Very little energy is required to both grow and process the hemp into insulation (Kymalainen \& Sjoberg, 2008). Thicknesses generally start at $100 \mathrm{~mm}$.

9. Cellulose insulation is a low cost insulation, usually created from plant fibres (including straw and hemp), but can contain combinations of paper, cotton and sawdust. Cellulose insulation can be either loose fill or spray applied. When applied it is usually three times denser than fibreglass but its performance is equal to fibreglass generally (Al-Homoud, 2005).

\subsection{Challenges with the existing these Thermal Insulations}

There has been a shift recently away from the use of certain plastic petroleum based thermal insulations. Expanded polystyrene (EPS), extruded polystyrene (XPS) and extruded polyethylene (XPE) are losing the battle against polyurethane / polyisocyanurate (PUR or PIR) insulations. These newer insulations are not without problems though.

Most PIR insulations are faced with reflective aluminium foil, which is used to reflect back radiant heat as part of the insulation's working process (Miller et al, 2004). However, CFC gas, a recognized global warming emission, would be released into the atmosphere without it being contained within the insulation by these aluminium 
facings. This insulation also degrades over time, resulting in the insulation having a substantially higher U-value than the U-value advertised (Bradshaw, 2010).

On an environmental level, the impact of petroleum based plastics and refined oil is threefold. Firstly, the retrieval of oil cannot be considered as sustainable since the limited supplies remaining and the damage caused to the environment by retrieval is in direct opposition to the "green" energy alternatives.

Secondly, the refining process of crude oil and the processes involved in plastic and foamed plastic insulation component manufacture involve high greenhouse gas output emissions as a by-product and high energy consumption throughout the product's start to finish manufacturing ratios. The refining process relies on the combustion of fossil fuels for this heating, whilst the recovery units emit large amounts of methane and carbon dioxide, making the oil refining industry a significant source of emissions (Worrell \& Galitsky, 2005).

End of life disposal of the insulation products is the third level of this environmental impact "triangle". Traditional insulations are difficult to dispose of in an ecologically friendly manner. In the UK, the majority of insulation finds its way to landfill sites where it leaches toxins into the soil as it degrades (Rogers, 2005).

According to the Environment Agency (2012), there are approximately 3000 pollution incidents involving oil and fuels within the UK annually. Waste oils also have to be disposed of according to the controlled waste regulations. In the UK, $16 \%$ of all pollution incidents annually involve waste oil (Environment Agency, 2004).

Europe-wide, approximately 67 million tons of plastic waste is dumped in landfill sites annually. To combat the longevity of landfill plastic waste, additives can be added to the plastic at the manufacturing stage that will degrade the plastic to nothing in a matter of months (Gho, 2012). Also, oil and oil-based plastic will rapidly degrade with exposure to water, oxygen or sunlight (Earthtalk, 2012). Opinions are divided though, neoprene rubbery type plastics will resist all three (Massey, 2007), because plastic waste is relatively lightweight and landfill reduction targets operate on a weight based tipping system, this can discourage some local authorities from recycling their plastic waste (Davies, 2006). 
On the other hand, the sustainable thermal insulation products derived from paper, wool, hemp and cotton fibres have recently become available for use. Although they are environmentally friendly promising products, there are cost and thermal performance related issues about these products. The proposed approach of soap based insulation will be produced from recycled materials and cost effective with no end of life disposal issues.

\section{Research Hypothesis - Soap based insulation as an alternative}

Soap insulation, derived from soap in its most basic form, (fats, oils and wood ash residue) is natural (Letcavage, 2013), combining fats and lye will create a hard, crude soap mixture that once aerated and left to cool can be cut into slabs and surrounded in recycled plastic to create thermal insulation products. As mentioned earlier, trapped bubbles within the insulation can give the insulation its thermal properties.

\subsection{Key Factors for Soap Based Thermal Insulation}

It is required to identify some factors in the research in order to justify or discount the hypothesis of soap based thermal insulation. As stimulated from the literature review in section 2 that highlights some challenges for the existing petroleum and other thermal insulations such as capital cost, environmental cost, thermal performance, weight, end of life disposal. If the proposed hypothesis of soap based insulation can help to overcome those challenges, it would be possible to validate it. Therefore, these factors derived from the existing challenges are elaborated below.

For the soap based insulation casing to be durable enough to withstand on site knocks without breaking and retain its shape throughout its lifetime, the soap must be strong enough. In addition, the weight of the insulation is also important because the insulation will need to be handled safely on site without excessive loading on the structure's foundations.

Comparison of the environmental cost of both petroleum and soap insulation should justify and identify the damage created by both raw material retrieval and disposal of the finished products when they reach the end of their use. 
Financial cost is an important factor when deciding if a product will be a marketplace success. Therefore, the capital costs of polystyrene and polyisocyanurate insulation products should be compared with the soap based insulation.

For ease of use, the finished soap based products must also compare favourably with their petroleum counterparts in weight to size ratios. All of the products should be non-toxic under everyday normal circumstances, including the cutting and the possible subsequent inhalation of the micro-fibres released into the immediate atmosphere. The reason for this is attributed to both the health and safety manual lifting guidelines and the occupational health exposure timeline limits when handling particular products.

The most important factor for the comparison is the working thermal performance of established petroleum insulation products and the latest soap developments in rigid thermal insulations. After all, the products must work. The comparisons will indicate where improvements can be made in order to compete on a "like for like" basis.

Some factors were not considered crucial in the development of the insulation. These included the texture of the insulation casing for on-site handling over time and the range/depth of colour for the insulation casing, which may pose a minor problem for the visually impaired. Slight variations in the soap composition were regarded as unimportant for soap based insulation. Waste fat composition varies from animal to animal, species to species and lye will differ according to which woods are burnt. Although attempts would be made to keep each batch as similar as possible, a somewhat generic overview was taken regarding the soap manufacture. Aerated soap is aerated soap.

There may be some opposition regarding the use of animal by-products in the manufacture of thermal insulation. Whilst this may be an issue in theory, these waste products have already been created (not for the intention of making soap) and would ultimately find their way to the incinerators. Using this argument meant that using animal parts was not a crucial factor for consideration. Also, no surveys have been conducted as to how soap insulation will be accepted into the marketplace in comparison the more established insulations. Market research could be conducted nearer the time of manufacture. 


\section{Research Methodology and Process}

The aim of the paper is to test and experiment the hypothesis of whether or not soap based thermal insulation is possible as an alternative to the petroleum counterparts. The research attempts to apply the existing knowledge about thermal insulations in practice and diagnose their factual shortages in building insulations based on the scientific and practical facts, and then attempt to propose soap based insulation as an alternative to overcome the shortages through lab based testing and experimentation. The research encapsulates the aspects of experimental research that allows manipulating the variables to test the hypothesis and measure change.

\subsection{Research Process}

Experimental research is best suited to this type of methodology because this systematic approach to research consists of a series of soap related experiments that analyse the cause and effect relationship at each experiment cycles. In effect the researchers are manipulating the variables to control and measure the effect on the dependent variable (Leedy and Ormrod, 2001). Figure 2 reflects the research process and its stages within the experimental research in the paper. Each cycle is also handled through an iterative cycle of research process that includes diagnosis, experimental planning, experimentation and evaluation. Findings from the evaluation in a cycle are fed into the next experimental cycle for refinement and improvement.

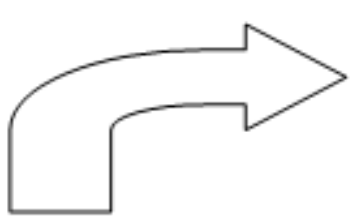

Evaluation: Review of findings and articulation of them according to the goals of the experiments

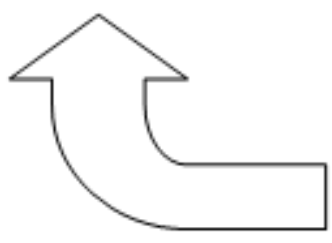

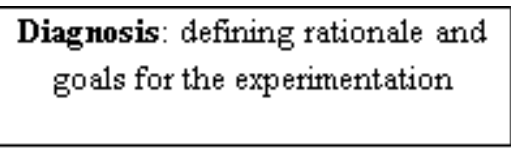
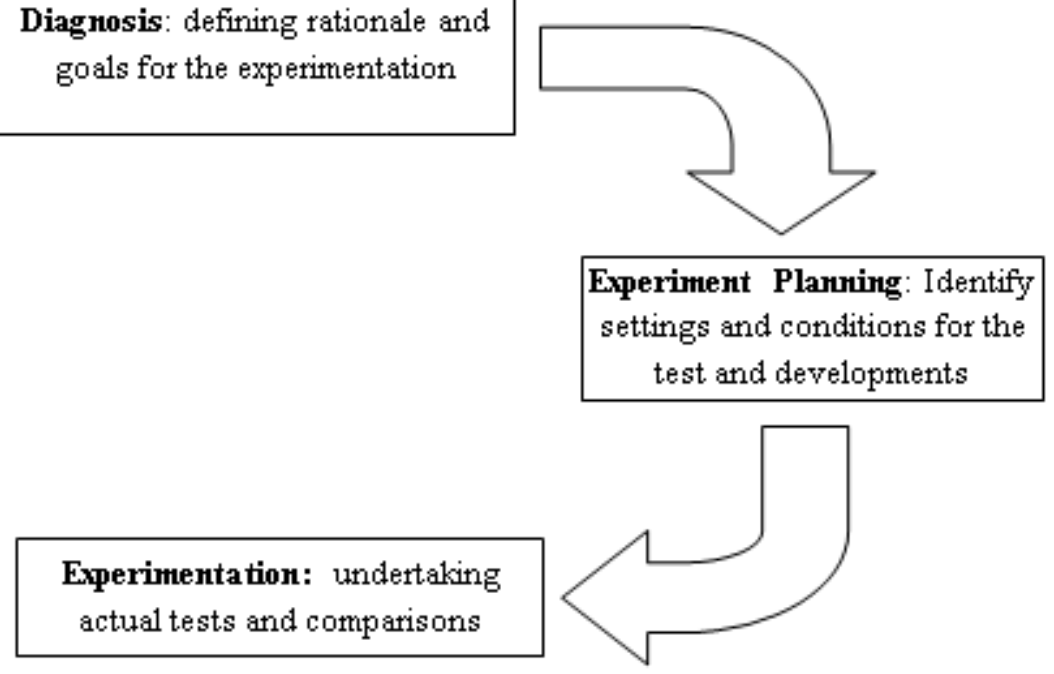

Figure 2: iterative cycle of experimental research 


\section{Cycle 1: Initial Crude Soap Production}

\subsection{Testing Protocols and Diagnosis for Crude Soap Production}

The overall aim is to create a thermal insulation that is capable of performing as a thermal insulation to ISO 8302, BS EN 12667, BS EN 12664 standards and the construction products directive (CPD) for product standard EN13162-EN 13171. This accreditation process is essential for the CE marking and thus ensuring that this product is suitable for retail in the green, sustainable insulation market. Salford Thermal Testing Laboratory is UKAS \& Ofgem accredited and is responsible for the thermal testing.

The testing results should identify a product that fulfils the testing and accreditation criteria and can be used in a variety of different situations, for example walls, floors and roofs. To put it simply, the ultimate goal is to create a soap based thermal insulation that performs to a standard that equals that of petroleum insulation. Failure will be measured by the soap insulation's failure to perform at an acceptable standard. However, if this is the case, at least the data collected may help to take the soap insulation research into a different direction until it does perform satisfactorily. Ultimately the insulations' thermal resistance capabilities will be the key.

Thermal resistance (R-value) is equal to the thickness of the material (in metres) divided by the conductivity of the material component. It is measured in $m^{2} \mathrm{~K} / \mathrm{W}$. The resistance of each component within an element are added together to reveal the extreme limits of resistance of the element overall. Generally, the higher the R-value is, the greater efficiency of the insulation used. One method of determining a material's R-value is by using the hot box method via a heat flow meter in figure 3 .

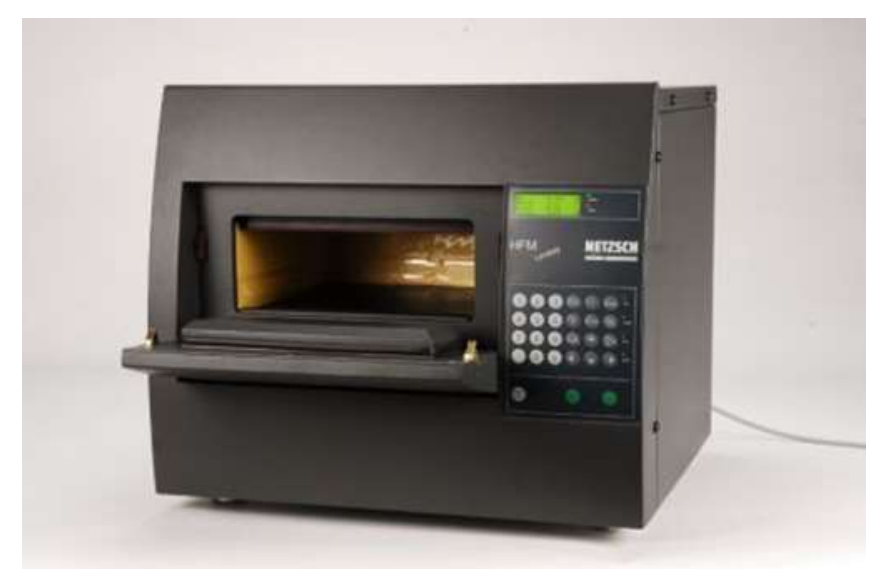

Figure 3: FOX 600 heat flow meter in the thermal lab 
All of the samples are stabilised to constant mass at $23 \mathrm{deg} \mathrm{C}$ and $50 \% \mathrm{RH}$ over periods ranging from 17 to 22 days, before testing. The actual testing is calibrated to ISO 8301, and performed in a "FOX 600 Heat Flow meter". The time length of each thermal conductivity test was 5 to 15 hours to give a \% equilibrium of $<0.4 \%$. The thermal resistance is evaluated from thickness / thermal conductivity as per the previous description.

Mixing oils/fat with lye creates a hard soap mixture as experimented in cycle 1 . It can be cut into rigid board and surrounded in plastic to create thermal insulation. As mentioned previously, the air bubbles within the soap will give the insulation its thermal properties. This insulation can act as a thermal barrier to prevent direct heat flow (conduction) through a solid wall, the movement of heat across an airspace from a warm object or environment to a cooler one (radiation) and the movement through air when air is warmed (convection). Therefore, the vision is to produce hard soap material from lye and various animal and vegetable fats.

\subsection{Experiment Planning for Crude Soap Production}

The actual manufacturing process involves adding the lye to water and mixing it with heated oil, whilst both ingredients are stabilized at a temperature of $40^{\circ} \mathrm{C}$. The mixture is blended until it thickens (achieves trace) and then poured into a mould to set (saponification). The process of saponification setting action reduces the lye soap mixture from a highly alkaline substance to one that is $\mathrm{pH}$ neutral. Generally the weight ratio for the component parts i.e. lye, water and oil is 1:3:7 respectively. The resulting mixture sets hard to create the basic starting rigid board soap samples for the proceeding experiments. These experiments involve strengthening and aerating the soap. Aerating the soap will make this product lightweight (and thermally efficient), the air bubbles within soap will give the insulation its thermal properties.

\subsection{Experimentation for Crude Soap Production}

\subsubsection{What is Lye and how it is produced?}

Ashes obtained from burnt wood leached into water for $7 / 14$ days changes the water into a hydroxide alkaline solution (Potasium hydroxide $(\mathrm{KOH})$ ) known as lye (Tro, 2012), which is a strong corrosive metallic base and the primary ingredient of drain cleaners. 


\subsubsection{Mixing the Lye with Oil (Animal Fat) for the Initial Crude Soap}

A potential of hydrogen test ( $\mathrm{pH}$ test) was carried out on the lye via a paper indicator testing strip. This was to determine the soap's acidity or alkalinity. The mixture was confirmed as alkaline registering a confirmation of 14 on the indicator testing strip. This is the highest strength of alkaline shown on a standard measuring strip ( 1 being the strongest acid, 8 being neutral). All subsequent soap mixtures also registered at 14 when initially mixed. $125 \mathrm{~g}$ of lye was then placed into containers for use in the soap test samples. Two soap samples were produced from the mixture of the Lye (potassium hydroxide) and beef fat $(125 \mathrm{~g}$ of $\mathrm{KOH}$ and $250 \mathrm{~g}$ of fat). While one sample was blended and left to solidify, $40 \mathrm{~g}$ of common salt was added to the other sample, then blended and left to solidify. The results were as follows:

- The Sample 1, which was the potassium hydroxide soap without salt, set to a semi solid state, somewhere between a liquid and a solid.

- The Sample 2, which is the potassium hydroxide soap with salt, -in effect the $\mathrm{KOH}$ is now converted to $\mathrm{NaOH}$ as a result of mixing with salt set solid over a 10 minute period.

The soap production process was repeated with different fats such as beef fat, pork fat, palm oil, used waste vegetable oil and used waste engine oil at the same proportions. The soap setting times for different fats/oils are shown in Table 1.

\begin{tabular}{|c|c|c|}
\hline Oil ingredient & Time achieve trace & Setting time (solid) \\
\hline Beef fat & 90 seconds & 10 minutes \\
\hline Pork fat & 2 minutes & 1 hour \\
\hline Palm oil & 5 minutes & 1 hour \\
\hline Waste vegetable oil & 6 minutes & 30 hours \\
\hline Waste engine oil & 12 minutes & 60 hours \\
\hline
\end{tabular}

Table 1: Soap setting times

\subsection{Evaluation of the Findings from the Experimentation}

As seen from the "soap setting time" table above, beef, pork and palm oil have similar consistencies and create soap over a broadly similar time-frame. This is because the proportions of fats within the oil have a direct bearing on the length of time required for the soap to set hard. It is noted that the waste engine oil used in the soap sample failed to set into a hard solid soap, but turned into a soft, flexible, 
"rubbery" material as shown in figure 4a. Therefore, soap production from waste engine oil was left out at that stage, the research continued on the other four fat/oils as they set hard, as seen in figure $4 b$ (Samples sized at $200 \mathrm{~mm} \times 100 \mathrm{~mm} \times 40 \mathrm{~mm}$ ).

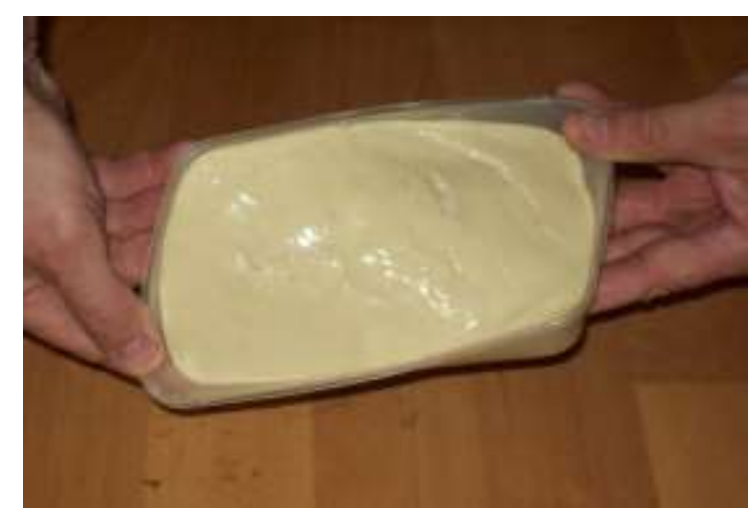

Figure 4a: This waste engine oil soap remained in a "blancmange" state

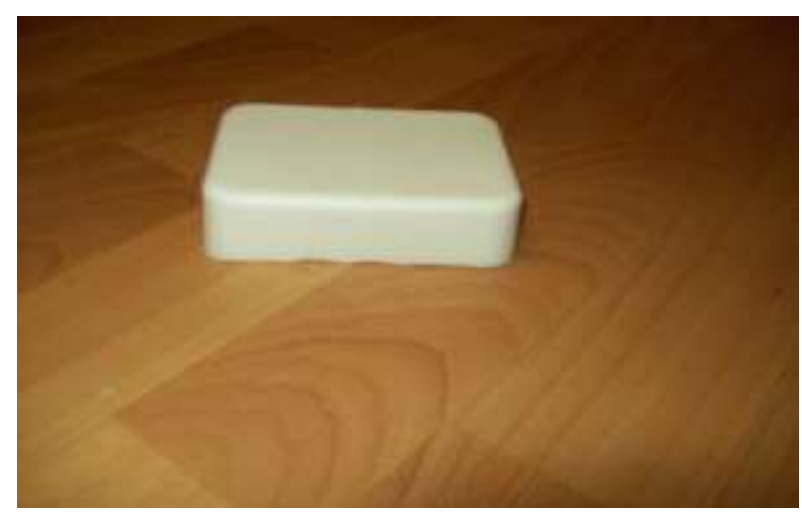

Figure 4b: Block of hard, solid, waste vegetable oil soap

\subsubsection{Additional Characteristics Required From the Soap Insulation}

Regarding the parameters of soap insulation, there are no established rules on how the processing, manufacturing or component combinations should be done. This is largely because soap insulation is a new concept and the cycle of improvement and testing are ongoing. However, the ingredients should be natural or recycled to a large extent wherever possible, for example, using bio-plastics and waste products.

\subsubsection{Vermin and Insect Repellant}

Both rats and mice will gnaw or eat plastic, especially if there is something edible beyond it. They will (and do) eat soap. In order to prevent this, a rodent repellant should be used in the insulation manufacture. For a natural repellant, vitamin D3 nutrient will be tested. D3 is essential for human health, but lethal to rodents. "As one of the safest substances known to man, vitamin D toxicity is very rare. In fact, "people are at far greater risk of vitamin $D$ deficiency than they are of vitamin $D$ toxicity" (Vitamin D council, 2012). According to the Jones (2008), Vitamin D is lethal to rodents because it can cause fatal elevated calcium levels in the blood and or heart attacks (hypercalcemia). When sealed watertight, the plastic casing surrounding the soap will also be enough to prevent even the most determined of insects from gaining entry. 


\subsubsection{Moisture Resistance}

A small insulation test sample (weighing $262 \mathrm{~g}$ ) made from aerated soap surrounded with watertight bio-derived polythene was constructed (Figure 5) and placed firstly in a freezer and then secondly to an outside area that was exposed to the elements. The temperature of the freezer was a constant $-18^{\circ} \mathrm{C}$ whilst the outside temperature ranged from $-4^{\circ} \mathrm{C}$ to $6^{\circ} \mathrm{C}$. Outside the samples were exposed to both sunlight and frost, but also snow and rain. The samples remained in both the freezer and outside for 28 days, and then placed in a real cavity situation for 6 months. None of the samples showed any adverse effects to the low or fluctuating temperature differences.

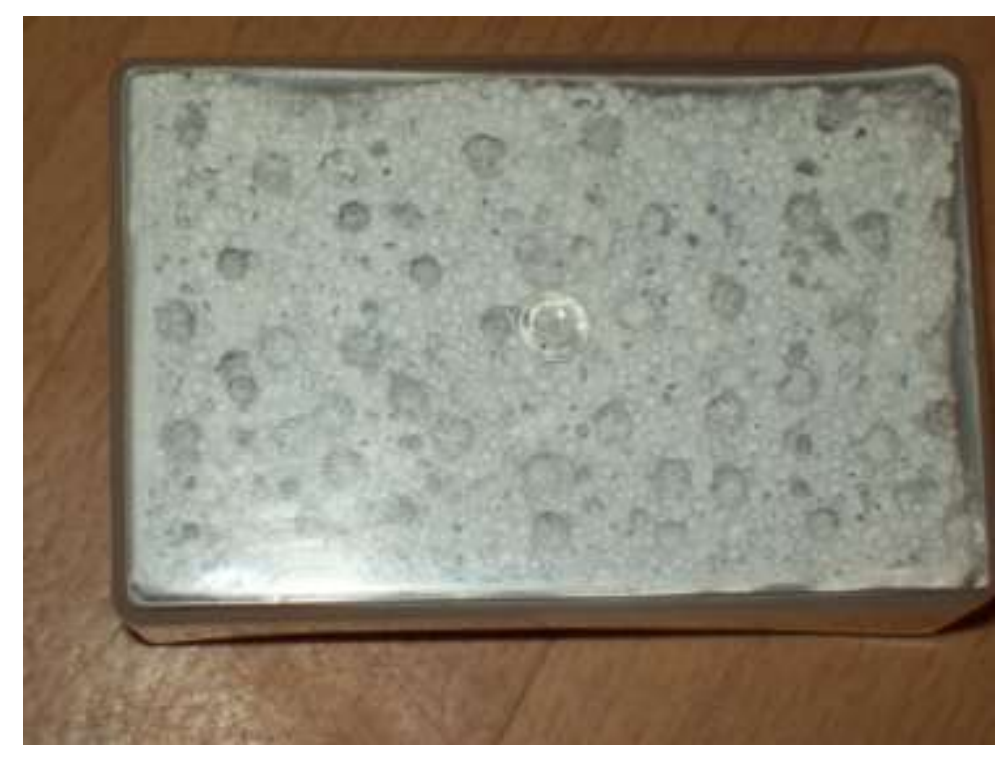

Figure 5: Soap Sample Surrounded with transparent Plastic Casing

\section{Cycle 2: Soap aeration for Light-weighted Thermal Resistance}

The review of soap with no additives, soap with added Straw, Soap with Added Expancel, Soap with Added Paper Spheres, Soap with Polythene high-density (PEHD) Spheres, Soap with Added Ice, Soap with Added Sodium Bicarbonate ( $\mathrm{NaHCO} 3$

\subsection{Diagnosis for Soap Aeration}

As experimented in cycle 1, using recycled materials, soap is produced but it is relatively heavy to be used for thermal insulation in comparison to its petroleum 
counterparts. For example, a $300 \mathrm{~mm} \times 300 \mathrm{~mm}$ sample of polystyrene insulation (at $50 \mathrm{~mm}$ thickness) weighs $67 \mathrm{~g}$. The same sized sample in polyisocyanurate weighs $135 \mathrm{~g}$. Aerated soap insulation surrounded in a lightweight plastic case weighs in at $1843 \mathrm{~g}$ for a sample of the same size.

To reduce the weight of the soap, more aeration bubbles of a larger size per the same volume area were required. It was discovered that using beef fat as the primary soap ingredient made the soap set quickly. This meant that although the soap did aerate to a certain extent, the bubbles never had a chance to fully develop before the soap set hard. Because of this a change the composition of the fat would be required to prolong the soap setting time.

Melted beef fat and vegetable oil added at a ratio of $70 \%-30 \%$ respectively should slow down the setting time and allow the bubbles to form over a longer period. The weight of the plastic casing could also be reduced by $50 \%$ by using $1 \mathrm{~mm}$ PEHD instead of $2 \mathrm{~mm}$. Therefore, the aim in cycle 2 experimentation is to reduce the weight of soap product to make it usable in comparison to petroleum counterparts through some differing aeration processes.

\subsection{Experiment planning for Soap Aeration}

As mentioned earlier, to make the soap lightweight and thermally efficient, it is necessary to aerate the soap mixtures, for which various methods of aerating soap were experimented. Air pumped into the liquid soap mixture via a compressor was considered, as well as pumped oxygen and helium gas. However, the addition of paper fibre balls, polythene balls, ice spheres, straw, "Expancel" microspheres and the vacuum air removal methods were actually tried. A variation of the microsphere aeration method was planned by using bicarbonate of soda. The methods used for aerated soap production are explained in the next section.

A sample of soap was mixed using the $250 \mathrm{~g}$ beef fat and $125 \mathrm{~g}$ of lye. This was an identical ingredients mix used for the subsequent soap batches. However, this initial mix has no aerating additives and considered as the control soap for comparison against the soap with additives. 


\subsection{Experimentation of Soap Aeration}

The subsections below explain the soap experimentation with different additives, which are, in section 4, then compared in weight with the control soap that has no additives.

\subsubsection{Soap with Added Straw}

The use of the short fibres of straw into the coarse soap is a way for aeration since straw is hollow and is a good insulator. It is a by-product of farming and is totally biodegradable. For the soap experiment, $15 \mathrm{~g}$ of straw cut into lengths of $10 \mathrm{~mm}$ $15 \mathrm{~mm}$ were added to a soap sample mixture. The additive equated to $50 \%$ of the soap mould's cubic volume.

\subsubsection{Soap with Added Paper Spheres}

Small, hollow, dried waste paper based spheres can be introduced into the soap composition. These can be lightweight cellulose fibres used as stabilizing additives to stone mastic asphalts and hot rolled asphalts (highways), or the more paper based used in art and craft hobbies. The paper can be recycled from low quality products such as newspapers etc. The size of these particles is typically $10 \mathrm{~mm}-$ $15 \mathrm{~mm}$.

An identical base mixture is created, but this time with the addition of $37 \mathrm{~g}$ of $15 \mathrm{~mm}$ paper balls. This $37 \mathrm{~g}$ equated to approximately one half of the soap mould cubic area by volume. This left a sufficient volume of soap to bind the mixture together for the strength of the product.

\subsubsection{Soap with PEHD (Polythene High Density) Spheres}

An alternative to paper is to use small $(10 \mathrm{~mm})$ hollow plastic balls made from waste PEHD. These are also extremely lightweight and should also give the insulation good thermal properties. This batch of soap was made in an identical way as the previous straw and paper ball additive soaps, but this time those additives were replaced with $25 \mathrm{~g}$ of $10 \mathrm{~mm}$ PEHD hollow spheres. The results were recorded.

\subsubsection{Soap with Added Expancel Microspheres}

Expancel microspheres are tiny spherical particles that expand many times from 
their original size with heat. Thus, already expanded microspheres can be incubated into a soap mixture. It does not only aerate the mixture, but also gives the finished structure compressibility and lightweight properties, which is ideal for insulation products.

The soap mixture, as with the previous test samples, was of identical proportions. The water was heated to $100^{\circ} \mathrm{C}$ in order to initiate a reaction from the microsphere powder. The Expancel was weighed at $0.5 \mathrm{~g}$ (4 tablespoons) and added to the water and lye mixture. The normal process of blending to achieve trace, and the pouring of the liquid soap into the mould to cure was completed. The weight of the product was recorded one week later.

\subsubsection{Soap with Added Ice}

The rationale behind this idea was that ice particles would be another method of aerating the soap. The ice would be introduced into the mix and as the temperature of the soap increased, and thus solidified, the melted ice would leave air pockets throughout. This should give the product lightweight properties.

Another batch of soap was mixed but this time $10 \mathrm{~mm}$ ice cubes were added. The ice was added to a batch of trace soap liquid but the soap immediately solidified on contact (with the ice). A test liquid soap mixture was introduced to a container of cold water and this soap also solidified instantly.

\subsubsection{Soap with Added Sodium Bicarbonate $\left(\mathrm{NaHCO}_{3}\right)$}

A bicarbonate of soda and vinegar foaming agent was compiled, at a ratio of two teaspoons to four respectively. This mixture foamed violently immediately the vinegar and soda came into contact with each other. This froth was introduced into the soap at the soap's liquid stage. The mixture was blended together. Observation revealed that the soap then separated into distinct layers. Soap occupied the bottom two thirds of the soap mould. The top third was a clear liquid with a salt glazed surface. A potential of hydrogen strip revealed the liquid to be an acid with a $\mathrm{pH}$ of 5 , whilst the soap below was alkaline with a $\mathrm{pH}$ of 13 . The liquid was drained off and the soap was left to solidify. However, the soap failed to set firm and remained in a gel state. It also remained in a highly alkaline state. 
When compared with the control (soap with no additives), the sodium bicarbonate soap was slightly lower in weight than the control. However, the soap did not set hard enough to consider for use as an insulation material. The soap structure had been considerably weakened by the addition of sodium bicarbonate and so this product was deemed unsuitable for purpose.

\subsubsection{Aerated Soap with Vacuuming}

Another batch of aerated soap was produced via air into the soap mixture under pressure. This would take place in a hermetically sealed container, with the air being sucked out from this container, creating a vacuum inside. This removal of air should create bubbles within the soap before it solidifies.

The soap mixture was poured into a compressed gas (nitrous oxide) dispenser. The soap was then fired under pressure into a plastic box with a sealable lid, which had a previously cut $5 \mathrm{~mm}$ hole through its surface. The box was placed into a PVC vacuum bag and the bag opening zipped was closed. The vacuum hole in the bag was aligned to the hole in the box lid. The air was then vacuumed out of both the bag and the container.

The soap was weighted and the results were recorded as $29 \%$ lighter than the control soap of equivalent cubic volume. The soap was then dissected to examine the bubble content (figure 6). Although the soap was aerated, the bubbles were small (approximately 1-3mm width generally). However, with the preliminary experimentation into aerating the soap successful, the method was clear to refine and expand on the results to improve its overall thermal efficiency capabilities.

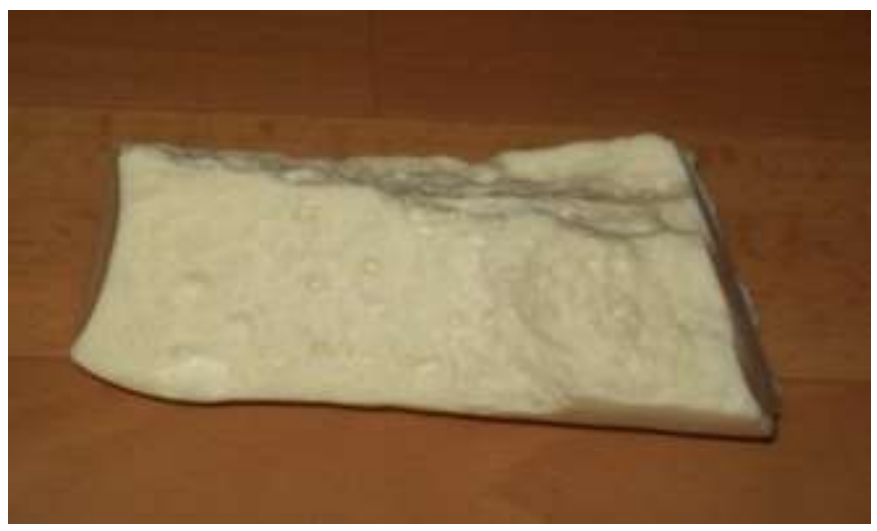

Figure 6: aerated soap created by the vacuum method 


\subsection{Evaluation of the findings from the Experiments}

Using the vacuum method of aeration, a melted beef fat and vegetable oil combination mixed at a ratio of $70 \%-30 \%$ respectively was tried. This did slow down the setting time and increased the bubble size to $5-7 \mathrm{~mm}$. This was an increase in size of approximately $50 \%$ over the previous vacuum method sample. This vacuum method of aeration exceeded expectations and slightly out- performed the added expanded microsphere aeration method.

All of the soap samples were each sized at $120 \mathrm{~mm} X 120 \mathrm{~mm}$, and $40 \mathrm{~mm}$ thick. After the production of the soap samples were dried, a moisture content reading was taken for each sample. When all of the samples had an identical reading of $35 \%$ (the moisture content of a shop brought control sample), the samples were weighed in grams. The results are recorded in the graph in Figure 7.

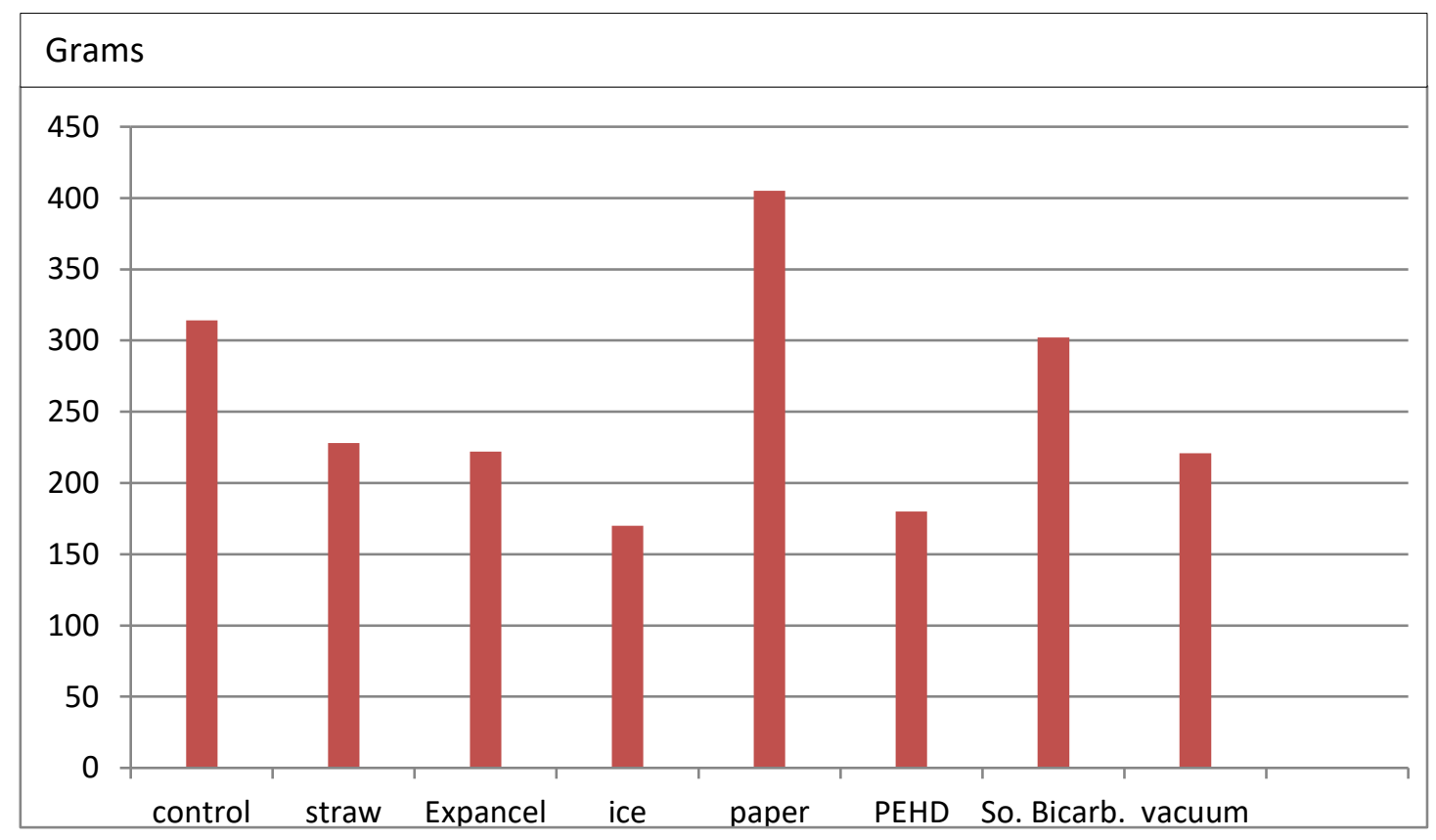

Figure 7 shows how additives affect soap weight

Table 2 below shows the weight percentage difference between the control soap and the soaps with the aerating additives.

Results showed that soap with added paper balls increased in weight. The reason for this is that the lightweight paper balls absorb and retain moisture from within the 
mixture, thus trapping the moisture inside of the sample, whilst the rest of the soap dries out.

\begin{tabular}{|c|c|l|}
\hline Paper balls $^{*}$ & $29 \%$ & Heavier than the control \\
\hline Plastic balls & $43 \%$ & Lighter than the control \\
\hline Ice balls & $46 \%$ & Lighter than the control \\
\hline Straw & $27 \%$ & Lighter than the control \\
\hline Expancel & $29 \%$ & Lighter than the control \\
\hline Sodium bicarbonate* $^{*}$ & $4 \%$ & Lighter than the control \\
\hline Vacuuming $^{*}$ & $29 \%$ & Lighter than the control \\
\hline
\end{tabular}

Table 2 Weight Difference Between soaps ( ${ }^{\star}$ Discontinued from further study)

The worst performers, soap with the paper balls, ice and baking powder were discontinued from this study with a view to possible investigation in the future. Out of the seven samples tested, only four moved on to the next stage: these are soap with plastic balls, straw, expanded microspheres and the vacuum method.

\section{Cycle 3: Improving Soap for Tensile Strength}

\subsection{Diagnosis for Tensile Strengthening}

For the insulation to withstand on site knocks without breaking and retain its shape throughout its lifetime, the soap must be strengthened. Although there was no actual benchmark figure for the insulation to achieve, it was deemed that the stronger the insulation was, the better it would be for its potential use. The weakest test samples would be classed as failures and discarded because of this reason. Therefore, further experimentation was needed with the addition of cotton thread fibres, wool fibres and the animal glue dispersed within the mixture at the soap's liquid stage before it hardens.

\subsection{Experiment Planning for Tensile Strengthening}

In the experimentation plan, the purpose of testing was to measure the strengthening ability of the additives in the soap as a whole. One soap sample contained no strengthening measures, and this was used as the control soap. Different soaps will give different readings due to their ingredients and composition with different additives (cotton thread fibres, wool fibres and animal glue). All four samples were sized at $100 \mathrm{~mm} \times 100 \mathrm{~mm}$ surface area, $25 \mathrm{~mm}$ thick. The tensile strength of the soap samples were determined by using the following formula: The surface area (in 
inches squared) is subjected to apply loading in lb's (pound-force) shown in figure 8. In metric the following conversion applies.

$1 \mathrm{psi}=\frac{1 \mathrm{lbf}}{(1 \mathrm{in})^{2}}=\frac{4.4482216152605 \mathrm{~N}}{(0.0254 \mathrm{~m})^{2}} \quad \begin{aligned} & \text { Figure 8: shows the formula of how } \\ & \text { tensile strength is calculated }\end{aligned}$

The breaking point force was recorded. The applied load was divided by the soap surface area to determine the tensile strength of the soap. The tensile testing of the soap was performed and automatically calculated on a 1970's "Scott" tensile testing machine, with the breaking points of each soap sample recorded in psi.

\subsection{Experimentation of Soap Tensile Strengthening}

It was noted that the polymer (glue) soap failed to achieve trace when mixing, and although clearly mixed, did remain at a "milk" consistency, until eventually setting solid over 30 hours. Wool and cotton fibres were added to the soap samples at the mixing stage. This addition improved its tensile strength. The tensile breaking points for samples were recorded in figure 9 .

\subsection{Evaluation of the findings from Soap Tensile Strengthening}

It can be seen from the graph, soap with a glue additive fared the worst. On cutting into the soap, it was revealed that the soap had a denser composition compared to "normal" soap. Although wool fibres provide better tensile strength than cotton, it was unclear at this stage if the thicker woollen fibres would interfere with any future aeration procedures i.e. interfering with the bubbles and restricting the bubble size.

Also cotton tends to allow for improved dispersal within the mix, as opposed to "clumping" which can occur with woollen fibres because of the stray outer fibres which can become entangled with the neighbouring fibres. Because of this, for cycle 2 , it was deemed that the thinner cotton thread fibres would be preferable to use for the insulation samples in the follow up experimentations. 


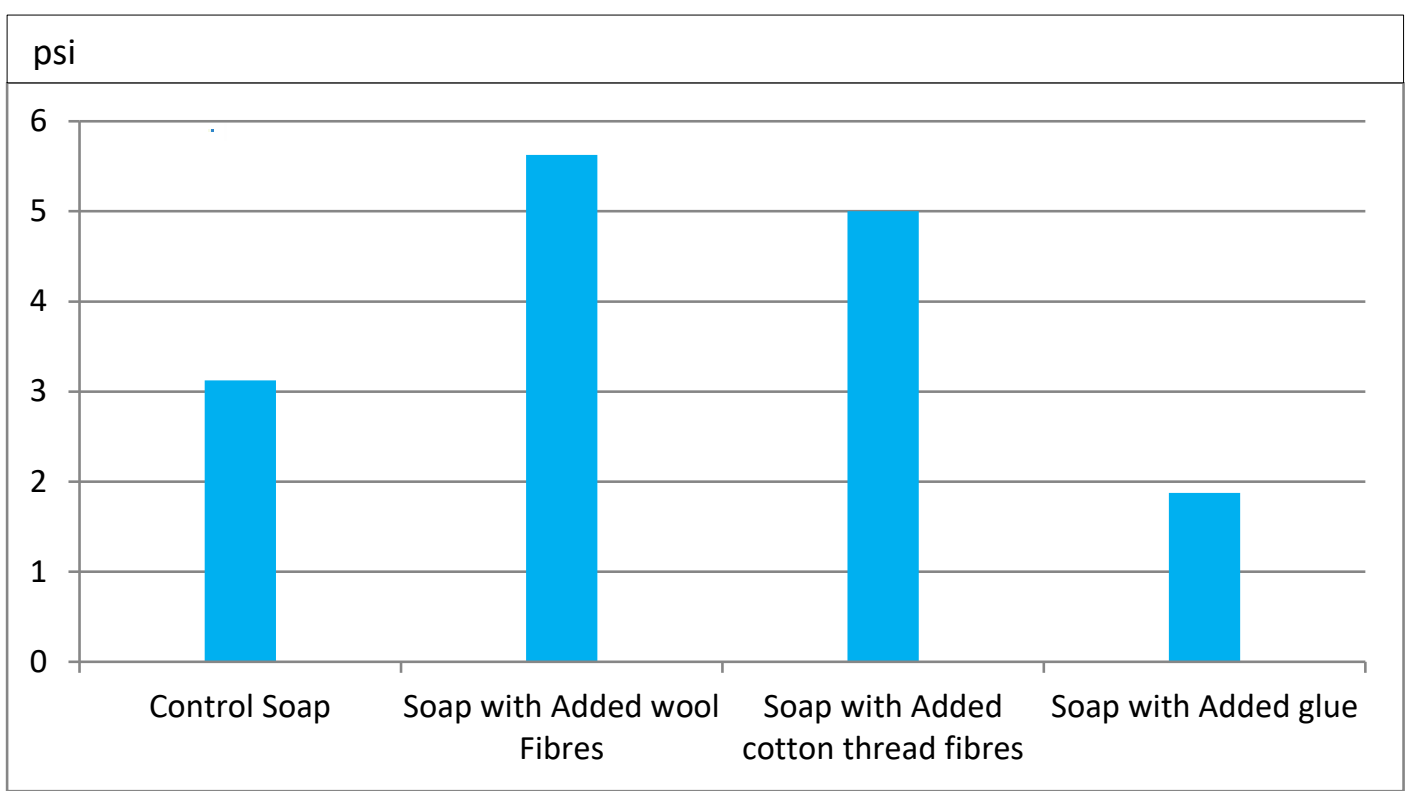

Figure 9 showing the tensile strengths for various soap mixtures

\section{Cycle 4: Tensile Testing of Strengthened and Aerated Soap}

Soap as a thermal insulation should be light-weighted and strengthened. Therefore, aerated soaps also should be strengthened enough to be a durable insulation material. The samples consisted of four previous mixes aerated with straw, hollow plastic spheres, Expancel microspheres and the vacuum method. These aerated mixes also included the cotton fibres for strength. Once hardened, the soap was tested to ascertain its tensile strength. All four samples performed lower than the unaerated samples. The actual strength of each sample is recorded in Figure 10.

The results indicate that aerating the soap samples decrease the tensile strength of the soap, even when the soap is strengthened. This could be a result of the aeration process making the soap less dense, which in turn makes the samples less resistant to compressive force. The molecular bonding could be weakened because of the breaking up of the linear structure as the pockets of air decrease the structural integrity, which then leads to lower tensile strength in comparison to the control soap that has no aeration. For example, the soap sample with the added plastic spheres performed the lowest since the soap failed to adhere the plastic to the same extent that it bonded to the straw and microspheres. 


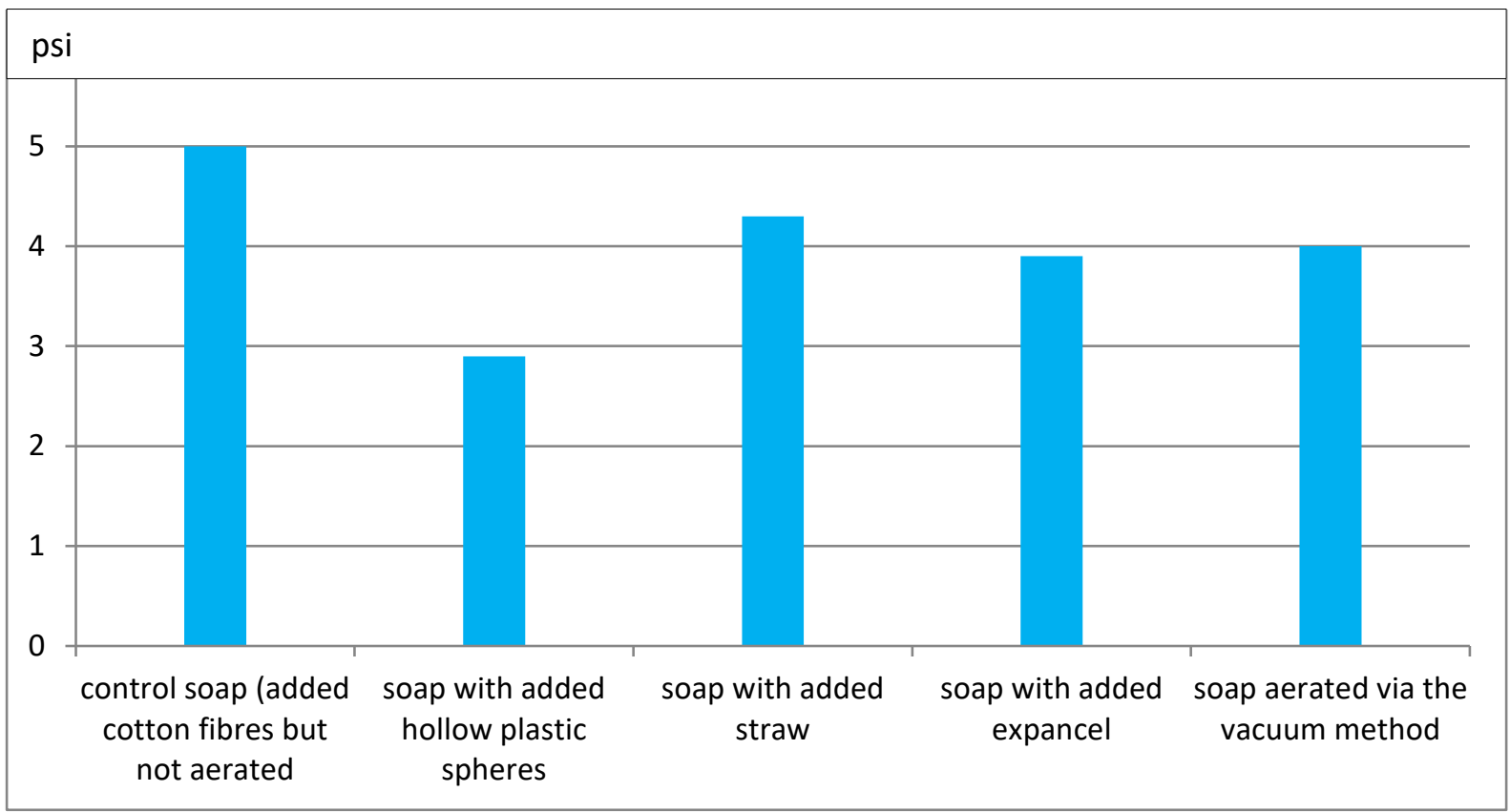

Figure 10: soap graph shows the tensile strength measurements

The worst performing samples are the samples within each particular testing group, that record the least favourable results compared to the others. This method of elimination ensures that only the better performing samples move on to the next stage. Because soap with plastic spheres fared worst, research into this soap was discontinued, while research into the other three sample types was continued. These are:

i) soap with cotton fibres and aerated vacuum method

ii) soap with added microspheres and cotton fibres

iii) soap with added straw and cotton fibres

\section{1. $\quad$ Testing the insulation for slump}

With regards to the effects of gravity on the insulation, downward force appears to increase in relation to the length it is acting upon. This can cause an object to deform as it succumbs to the physical force of gravity along its middle (deflection). Alternatively, also compression due to the objects own settling weight. This sample was placed in a vertical position against a wall and the outline of the soap was drawn on to the wall to act as a horizontal linear gauge (slump line). This would reveal any potential sagging in the soap sample. The sample was left in place for 60 days. If the sample had shown signs of slumping it would have been left in place until the 
slumping had stopped and then recorded. However, no movement in the sample casing or contents was observed. Figure11 shows the reinforced soap sample.

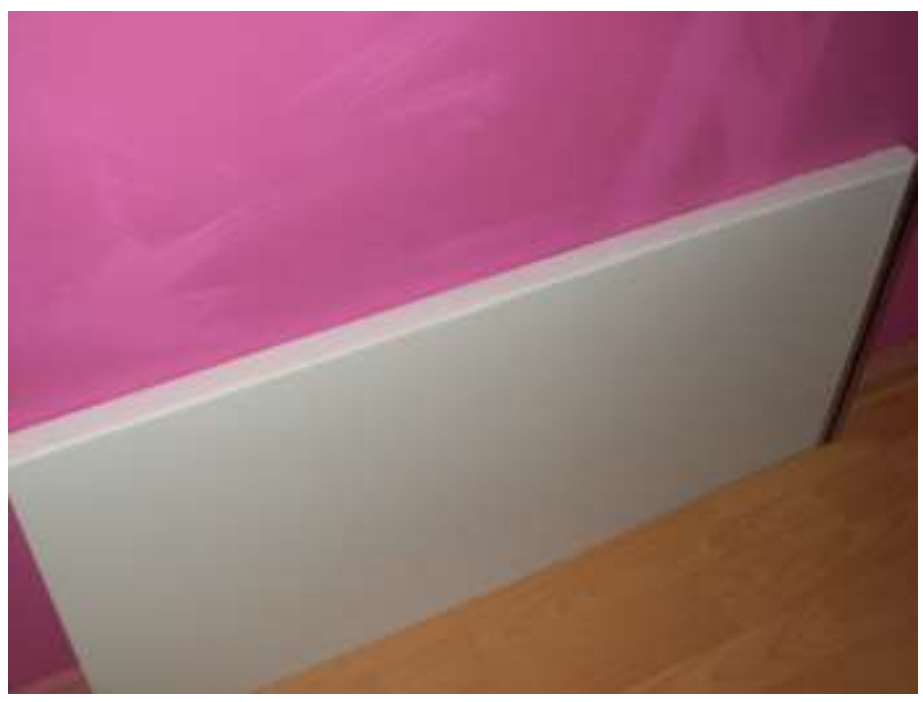

Figure 11: $420 \mathrm{~mm} \times 840 \mathrm{~mm}$ soap sample

\section{Cycle 5: Thermal Performance testing}

A sample testing cycle was established, focusing on the thermal resistance of the three final samples listed in section 7 of the paper. These samples were tested in the thermal lab of the Salford University using the heat flow meter shown in figure 2. All three samples were sized at $300 \mathrm{~mm} \times 300 \mathrm{~mm}$ and each sample's weight was recorded. They each had a thickness of approximately $50 \mathrm{~mm}$. The thermal resistance figure was identified by dividing the thickness of the sample by the thermal conductivity.

Sample 1 had a thickness of $0.0511 \mathrm{~m}$ and a thermal conductivity of $0.0746 \mathrm{~W} / \mathrm{mK}$. This equated to a thermal resistance figure of $0.684\left(\mathrm{~m}^{2} \mathrm{~K}\right) / \mathrm{W}$.

Sample 2 had a thickness of $0.0513 \mathrm{~m}$ and had a thermal conductivity of 0.0799 $\mathrm{W} / \mathrm{mK}$. This equated to a thermal resistance figure of $0.642\left(\mathrm{~m}^{2} \mathrm{~K}\right) / \mathrm{W}$.

Sample 3 had a thickness of $0.0511 \mathrm{~m}$ and thermal conductivity of $0.0989 \mathrm{~W} / \mathrm{mK}$. This equated to a thermal resistance figure of $0.516\left(\mathrm{~m}^{2} \mathrm{~K}\right) \mathrm{W}$.

Although all three samples show similar environmental and financial costs, and can be disposed of in an environmentally friendly manner, sample 1(vacuum method) weighed in at approximately $25 \%$ of the weight of sample 3 (straw), a big factor in 
moving sample 1 forward. Sample 1 also gave a better thermal performance than sample 3. For this reason Soap with straw was discontinued from further study.

Sample 1 was also lighter than sample 2 (microspheres) although showing a similar thermal performance. Because of the weight difference between sample 1 and 2, sample 2 was discontinued from further experimentation, whilst sample 1 became the foundational specification for soap based thermal insulation to build the next experiments off.

Although the initial thermal resistance values are not as successful as aimed, it should be remembered that these samples are the first stage testing and follow up experiments will build on these results for improvement. The testing and comparison of the three samples gave an opportunity to learn how to increase the $R$ values of the succeeding samples, and aeration by vacuuming looks promising.

For example, by increasing the ratio of bubbles to soap, the insulation matrix will become lighter and less dense. This will improve the thermal resistance of the soap sample, as the entrained air to solid (soap) ratio is increased. Changing the protective casing to a lighter material will also decrease the insulation weight further.

\section{Comparing the soap insulations with Petroleum Counterparts}

The successful aerated and strengthened soap samples were then compared with the petroleum counterparts such as Polystyrene and Polyisocyanurate in this cycle in order to justify or discount if soap based insulation can be an alternative to those petroleum counterparts. The factors identified in section 3.1 such as financial cost, environmental manufacturing cost, thermal resistance, thermal conductivity, weight, thickness, working performance (durability) and end of life disposal are utilised for this comparison.

Since soap based insulation is a rigid board type, only insulations of petroleum based rigid board types were compared. This meant that both fibreglass and multifoil insulations were omitted from this comparison. This is because of the multitude of performance variant types within the marketplace, the lowest performing petroleum based insulation, expanded polystyrene, was used a comparable, alongside the best performing petroleum based - foil faced polyisocyanurate. This eliminated the need to compare mid-performing thermal insulations such as extruded polythene (XPE) 
etc. Both expanded polystyrene and polyisocyanurate insulations give a benchmark to aspire to within the same insulation type category, whilst allowing for a scale to be established to show whereabouts soap insulation "is at" compared to these two. These findings are represented in table 3.

\begin{tabular}{|c|c|c|c|c|c|}
\hline Criteria & Sample 1 & Sample 2 & Sample 3 & $\begin{array}{c}\text { Expanded } \\
\text { polystyrene }\end{array}$ & $\begin{array}{c}\text { Polyisocyanurate } \\
\text { (Foil Faced) }\end{array}$ \\
\hline Financial Cost & 0 & 0 & 0 & 0 & 0 \\
\hline $\begin{array}{c}\text { Environmental } \\
\text { Manufacturing } \\
\text { Cost }\end{array}$ & 0 & 0 & 0 & 0 & 0 \\
\hline $\begin{array}{c}\text { Thermal } \\
\text { Resistance }\end{array}$ & $0.684\left(\mathrm{~m}^{2} \mathrm{~K}\right) / \mathrm{W}$ & $0.642\left(\mathrm{~m}^{2} \mathrm{~K}\right) / \mathrm{W}$ & $0.516\left(\mathrm{~m}^{2} \mathrm{~K}\right) / \mathrm{W}$ & $1.25\left(\mathrm{~m}^{2} \mathrm{~K}\right) / \mathrm{W}$ & $2.0\left(\mathrm{~m}^{2} \mathrm{~K}\right) / \mathrm{W}$ \\
\hline $\begin{array}{c}\text { Thermal } \\
\text { Conductivity }\end{array}$ & $0.0746 \mathrm{~W} / \mathrm{mK}$ & $0.0799 \mathrm{~W} / \mathrm{mK}$ & $0.0989 \mathrm{~W} / \mathrm{mK}$ & $0.04 \mathrm{~W} / \mathrm{mK}$ & $0.025 \mathrm{~W} / \mathrm{mK}$ \\
\hline $\begin{array}{c}\text { Weight } \\
\text { Thickness }\end{array}$ & $1,084 \mathrm{~g}$ & $1,843 \mathrm{~g}$ & $4,650 \mathrm{~g}$ & $67 \mathrm{~g}$ & $135 \mathrm{~g}$ \\
\hline $\begin{array}{c}\text { Working } \\
\text { Performance } \\
\text { (Durability) }\end{array}$ & $\mathrm{O}$ & $\mathrm{O}$ & $\mathrm{O}$ & 0 & $50 \mathrm{~mm}$ \\
\hline $\begin{array}{c}\text { End of Life } \\
\text { Disposal }\end{array}$ & $\mathrm{O}$ & 0 & 0 & 0 & 0 \\
\hline
\end{tabular}

Table 3: Soap insulation comparison table

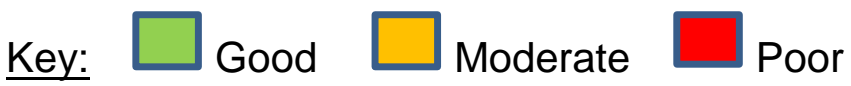

Results from the Thermal Testing Laboratory in Salford revealed the thermal resistance of each insulation type. Generally, the higher the thermal resistance figure, the better the given performance from the insulation. Firstly, the thickness of the sample was measured. This figure was divided by the thermal conductivity figure measured by the FOX 600 apparatus. The resulting answer gave the figure for thermal resistance.

Desktop surveys reveal that the financial and environmental costs of soap based thermal insulation are lower than both polystyrene and polyisocyanurate insulations. The end of life disposal scenario for soap insulation is better also. However, the results of the initial tests reveal that $100 \mathrm{~mm}$ thick aerated soap surrounded with a plastic casing would perform to an equivalent level of approximately $30 / 40 \mathrm{~mm}$ expanded polystyrene and $15 \mathrm{~mm}$ polyisocyanurate generally. These findings are 
represented in table 3. The results are further elaborated for each factor on the following page. These findings in the table are further elaborated below for each criterion

\subsection{Financial Cost}

The price of polystyrene insulation at $50 \mathrm{~mm}$ thickness averages at $£ 4.69 \mathrm{~m}^{2}$, whilst polyisocyanurate insulation sized at $50 \mathrm{~mm}$ thickness averages at $£ 10.07 \mathrm{~m}^{2}$. The average price per metre ${ }^{2}$ of soap based insulation, at a thickness of $50 \mathrm{~mm}$, is $£ 2.14$. The majority of this price is for the recycled plastic casing.

\subsection{Environmental Cost}

Compared to soap insulation, the journey from crude oil to polystyrene or polyisocyanurate thermal insulation is a relatively complex one. Petroleum based insulations can potentially bring both health and environmental problems. Crude oil is a mixture of many chemical constituents, although primarily hydrocarbons (chemicals composed of carbon and hydrogen). This oil in its raw form also contains several hundred chemical compounds including mercury $\left(\mathrm{Hg}_{2} \mathrm{C}_{12}\right)$, nitrogen $\left(\mathrm{N}_{2}\right)$, nickel $(\mathrm{Ni})$, benzene $\left(\mathrm{C}_{6} \mathrm{H}_{6}\right)$, iron $\left(\mathrm{Fe}_{26}\right)$, chromium $\left(\mathrm{Cr}_{24}\right)$, oxygen $\left(\mathrm{O}_{2}\right)$, xylene $\left(\mathrm{C}_{6} \mathrm{H}_{4}\left[\mathrm{CH}_{3}\right]_{2}\right.$ and toluene $\left(\mathrm{C}_{7} \mathrm{H}_{8}\right)$. Crude oil is heated and these chemical compounds are separated according to their density, for example, refined into petroleum, diesel oil, engine and heating oils, bitumen and heavy metals [40]. The burning of crude oil emits chemicals that may be detrimental to human health. These chemicals include carbon dioxide $(\mathrm{CO} 2) /$ monoxide $(\mathrm{CO})$, lead $(\mathrm{Pb})$, nitrogen oxides $\left(\mathrm{NO}_{2}\right)$, sulfur dioxides $\left(\mathrm{SO}_{2}\right)$, polycyclic hydrocarbons $\left(\mathrm{C}_{24} \mathrm{H}_{12}\right)$, and rapidly evaporating organic compounds (Botkin, 2010).

Soap insulation is both natural and green. The manufacture of soap and bio-plastic is clean. Furthermore, it should be noted that lye, although natural, can cause damage to the environment if released in large quantities. Thus, its use for soap production must avoid its release into the environment in large quantities. This is another indirect benefit of soap based insulation from environmental sustainability perspective. 


\subsection{End of Life Disposal}

The end of life disposal of thermal insulations is usually based on a 60 year lifecycle (NNFCC, 2008). Both natural and man-made fibre insulation may have accrued water sorption over this lifespan whilst petroleum based rigid board insulations may have degraded as to not perform properly (Norton, 2008). It is upon reaching this stage that much insulation are rejected and replaced. This waste insulation often finds its way to landfill where it slowly degrades, often releasing and leaching toxins.

As mentioned previously, at the soap insulations' end of life, the soap component insulation body can be melted down for re-use or possibly ground down to create an alkaline fertilizer $\left(\mathrm{CH}_{3}\left[\mathrm{CH}_{2}\right]_{\mathrm{n}} \mathrm{COON}_{\mathrm{a}}\right)$, giving the product a $100 \%$ end of life recyclability. Because of the soaps $\mathrm{pH}$ neutrality, this fertilizer should be compatible with both acid and alkaline soils.

\subsection{Insulation Weight}

Both polystyrene and polyisocyanurate insulations are lightweight. This makes for good on-site handling and a good weight to house foundation loading ratio.

As seen from the table, soap insulation surrounded with plastic does not perform as well as the petroleum counterparts. The worst performer was soap with added straw. As an example, this insulation sized at $450 \mathrm{~mm} \times 1200 \mathrm{~mm}$, at $50 \mathrm{~mm}$ thick would weigh in at $20.925 \mathrm{~kg}$. At $100 \mathrm{~mm}$ thickness, the insulation sheet would weigh $41.85 \mathrm{~kg}$. The maximum recommended manual lifting limit for 1 man is $25 \mathrm{~kg}$ and for a woman is $16 \mathrm{~kg}$. Calculating on from this, this weight would also have a detrimental effect on the bearing on a house foundation. An average, typical new 3 bedroom detached house has a floor area of $44 \mathrm{~m}^{2}$ (RIBA, 2011). This equates to approximately $130 \mathrm{~m}^{2}$ of wall insulation. This means that the walls would require approximately $241(450 \mathrm{~mm}$ X $1200 \mathrm{~mm})$ soap based cavity insulation slabs. At $50 \mathrm{~mm}$ thick this would put an additional load on the foundations of 5.061 tons. If the soap with straw combination insulation was $100 \mathrm{~mm}$ thick, then the additional loading would be approximately 10.122 tons.

Industry standard cavity wall insulation ranges from $50 \mathrm{~mm}$ to $100 \mathrm{~mm}$ thick generally, dependant on full-fill or partial fill is used. "Celotex SW3000" will have a lambda of 0.025-0.027W/mK (Celotex, 2014) and "Rockwool Cavity" will have a lambda of 
0.037 W/mK (Rockwool, 2011). Regarding lowering u-values, under the new Part L revision [which came in force in April, 2014], it is recommended that wall cavities increase in width to $150 \mathrm{~mm}$. It has been accepted by government however that is unlikely to happen and that increased insulation thickness will be required to floors and roofs to compensate.

\subsection{Thermal Resistance}

According to the comparison results, the soap insulations did perform poor in relation to petroleum counterparts in terms of thermal resistance. Therefore, second stage testing and experimentations will be carried out to improve the thermal resistance performance of the soap insulation. For example, surrounding soap with hemp or cork instead of bio-plastic casing and attempting a higher density of smaller aeration bubbles.

Through laboratory calculations and recent further actual laboratory testing, it is predicted that in general this improved soap insulation will not equal the equivalent thickness of basic expanded polystyrene. For example, 100mm soap based insulation will equal $50 \mathrm{~mm}$ expanded polystyrene insulation. This will be the equivalent of $25 \mathrm{~mm}$ polyisocyanurate thermal insulation generally. Further improvements to the aerated soap body should reduce the gap between soap and polyisocyanurate even further.

\subsection{Working Performance (Durability)}

Final factor of the testing has yet to be initiated to reveal how soap insulation will perform over the long term, although small aerated samples have been exposed to 6 months real world insulation placement and have performed without any adverse effects to the either their external or internal composition make-up. However, Slabs of soap insulation utilising straw as a component part were too heavy to be stacked upon each other, as would be required in a real world situation.

At a height of $3.3 \mathrm{~m}$, the compressive force of $51.150 \mathrm{~kg}$ acting upon the bottom insulation sample created a small yet significant split in the plastic casing. This could create a path for possible moisture ingress and as such, the failure of this heavy insulation meant that the soap/straw combination was discontinued. 
Working on the result that plastic cased insulation could fail with a $51.150 \mathrm{~kg}$ load applied, it was calculated that at a height of $8.3 \mathrm{~m}$, an equal weight of $51.150 \mathrm{~kg}$ would be produced using Expancel soap with a plastic casing. This height is possibly within the realms of a 3 storey building. This meant that plastic surrounded soap insulation with added Expancel as the bottom supporting slab, could also fail and so this insulation type was also discontinued.

Calculations reveal that the lighter plastic surrounded soap insulation aerated via the vacuum method should be adequate to use in a three storey property. It should be pointed out at this stage that the insulation does not necessarily have to be stacked in order to support the insulation above. It will largely depend on how the insulation is fitted or fixed to the structure.

\subsection{The Way Forward}

Experimental results have revealed that soap can be used as an insulation material since it has promising advantages in terms of cost and end life disposal. It has proved to be a thermal insulate even though it is relatively poorer than its petroleum counterparts in terms of thermal resistance. However, ongoing improvements to both the insulation body and casing look promising. Next stage testing will see an addition of naturally waterproof, pure liquid keratin dispersed within the soap mixture. This will change the composition of the soap, making the soap body moisture resistant. This will be essential to the insulation if the protective casing is to be made from lightweight, breathable hemp or cork. The soap casing should be fire resisting in as far as reasonably practicable. A flame retardant solution can be manufactured without the need for expensive or toxic chemicals. Ammonium phosphate $\left(\mathrm{NH}_{4}\right)_{3} \mathrm{PO}$ is commonly used as a flame retardant. It is non-toxic and can be spray applied to the insulation casing. Ammonium phosphate is a derivative of ammonia $\left(\mathrm{NH}_{3}\right)$ commonly found in animal dung or urine and weak phosphoric acid $\left(\mathrm{H}_{3} \mathrm{PO}_{4}\right)$ derived from limestone and sea bed sediments. Common materials found throughout the world.

The findings have helped to define a clear pathway in the research for how to improve the soap material to be capable of performing as a thermal insulation according to ISO 8302, BS EN 12667, BS EN 12664 standards and the construction products directive (CPD) for product standard EN13162-EN 13171. This 
accreditation process is essential for the CE marking, which is a mandatory conformity marking for certain products sold within the European Economic Area, ensuring that this product is suitable for retail in the green, sustainable insulation market. The Thermal Testing Laboratory in Salford is accredited for supplying such certification.

The insulation samples used for the further experimentation will be sized at $300 \mathrm{~mm}^{2}$ and $50 \mathrm{~mm}$ thick. It will be possible to calculate the thermal resistance of $100 \mathrm{~mm}$ thick samples from the results of the $50 \mathrm{~mm}$ thick samples. In order to identify the best performing specification of soap insulation, further continuous testing in the thermal lab (http://www.salford.ac.uk/energy) and in the real world setting situations will be carried out.

The future tests will also consider the insulation performance when placed in "reallife" heat, humidity and temperature fluctuation situations. The projected results should identify products that fulfil the testing and accreditation criteria so that it can be used in a variety of different situations, for example walls, floors and roofs. The best performing samples will be compared on a like-for-like comparison basis with both polystyrene and polyisocyanurate thermal insulations.

\section{Conclusion}

The paper explained the attempt to develop a soap making process for thermal insulation. Findings so far show that soap based thermal insulation is possible.

Various mixtures and manufacturing methods employed have been discarded. These included pure potassium hydroxide soap, soap derived from waste engine oil and soap mixtures with added paper balls, ice, glue, plastic spheres and sodium bicarbonate. The soaps carried forward to the next stage included the use of the methods that were successful for the soap aeration and strengthening processes such as $\mathrm{NaOH}$ derived soap made with animal and vegetable oils, reinforced and aerated with straw, cotton fibres, Expancel and by use of the vacuum method.

Finally, the produced soap insulations aerated soap samples are benchmarked with the petroleum counterparts in terms of financial cost, environmental cost, thermal resistance, weight, working performance and end of life disposal. From the comparisons, soap insulation is better performing than the petroleum counterparts in 
terms of financial and environmental costs and end of life disposals, while it does perform relatively poorer in weight, thermal resistance and working performance. However, the soap with cotton fibres and aerated with vacuuming is the most promising sample in the comparisons, showing that soap based thermal insulation is possible. Thus, further improvement and refinement to the product and manufacturing methods will be carried out next in the phase of the research.

Soap based thermal insulation is a new concept and the soap development processes and testing are still ongoing. Early indications reveal that soap can perform as a thermal insulation, but at what constitution, density and thickness is still to be determined. The thickness and aeration density of the insulation will be the key factors for determining if the insulation is practical.

\section{References}

Al-Homoud, M,S. (2005) Performance Characteristics and Practical Applications of Common Building Thermal Insulation Materials. Building and Environment. Vol.40. Issue 3: Elsevier, pp.253-366.

Approved Document Part L1A,B: Conservation of Fuel and Power. (2010). Norwich: The Stationary Office.

Approved Document Part L1A,B: Conservation of Fuel and Power. (2013). Norwich: The Stationary Office.

Bejan. A, (2004) Convection Heat Transfer Indiana: Wiley, p.150.

Berkeley National Laboratory, Berkeley, CA. Available from: http://www.energystar.gov/petroleum/energy guide.pdf. [Accessed 20/07/12].

Botkin,D.B. (2010). A Scientists Guide to Energy Independence: Oil. Retrieved 12 April, 2012, from http://www.ftpress.com

Bradshaw, V. (2010) The Building Environment: Active and Passive Control Systems. $3^{\text {rd }}$ ed. New Jersey: Wiley.

Butts, J.B \& Rich, K.L. (2010) Philosophies and Theories for Advanced Nursing Practice. Ontario: Jones \& Bartlett Learning, p.184.

Celotex Wall Insulation. (2012) Insulation Benefits. [Online] Available from: http://www.celotex.co.uk. [Accessed 04/05/12]

Celotex Wall Insulation. (2010) Insulation Types. [Online] Available from: http://www.celotex.co.uk. [Accessed 09/09/11] 
Celotex Wall Insulation. (2014) Celotex Products. [Online] Available from: http://www.info@celotex.co.uk. [Accessed 04/05/14]

Davies, G.B.H. (2006) Environmental Packaging. Unpublished thesis (PhD), University of Brunel, London.

DeGunther, R. (2010) Solar Power Your Home for Dummies. 2nd ed. Indiana: Wiley, p.179.

Earthtalk. (2012) Do Biodegradable Items Really Break Down in Landfill. Available from: http://www.environment.about.com [Accessed 02/12/12].

Environment Agency. (2012) Inland oil pollution. Available from: http://www.environment-agency.gov.uk. [Accessed 03/04/12].

Environment Agency. (2004) Inland oil pollution. Available from: http://www.environment-agency.gov.uk. [Accessed 03/04/11].

Gho, J.G. (2012) TDPA in Plastic. Available from: http://www.epi-global.com [Accessed 02/08/12].

Goodall, C. (2012) How to Live a Low-Carbon Life: The Individual's Guide to Stopping Climate Change. London: Earthscan, p.231.

Grosso, A. (2002) Soapmaking: A magickal Guide. New Jersey: New Page Books, p.51.

ICAEN (Institut Catala D'Energia). (2004) Sustainable Building Design Manual: Sustainable Building Design Practices. Vol.2. New Delhi: The Energy \& Resource institute, p.65.

Jones, G. (2008) Pharmacokinetics of Vitamin D Toxicity 1,2,3,4. The American Journal of Clinical Nutrition. Vol.88. Issue 2: Custom Publications, pp.167-171

Kirk,D. (1997) Environmental Management for Hotels: A Students Handbook.

Oxford: Butterworth-Heinemann, pp.87, 88.

Kutz, M. (2011) Applied Plastics Engineering handbook: Processing and Materials. London: Elsevier, p.411.

Kymalainen, H, R. \& Sjoberg, A, M. (2008) Flax and Hemp Fibres as Raw Materials for Thermal Insulations. Building and Environment. Vol.43. Issue 7: Elsevier, pp.1261-1269.

Leedy,P.D and Ormrod, J.E. (2001) Practical Research: Planning and Design. $7^{\text {th }}$ ed. New Jersey: Prentice Hall, p.9.

Letcavage,E. (2013) Natural Soap Making. Pennsylvania: Stackpole.

Long, M. (2006) Architectural Acoustics. California: Elsevier Academic Press, p.335. 
MacKay, D.J. (2009) Sustainable Energy-Without the Hot Air. Cambridge: UIT Cambridge Ltd, p.5.

Massey, L.K. (2007) The Effects of UV Light and Weather on Plastics and Elastomers. $2^{\text {nd }}$ ed. Norwich: William Andrew, p.373.

Miller, M.R; Miller, R. \& Leger, E. (2004) Complete Building Construction: All New $5^{\text {th }}$ Edition. Indianapolis: Wiley. p424.

Nave, R. (2010). Fabric Heat Transfer Calculations. Retrieved 140ct.2013 from http://www.reviewpe.com/penotes/heat

NNFCC. (2008). Life Cycle Assessments of Natural Fibre Insulation Materials.

Retrieved 24 Oct. 2012 from http://www.eiha.org.

Norton, A. J. (2008). The Lifecycle Assessment and Moisture Sorption Characteristics of Natural Fibre: Thermal Insulation Materials. (Unpublished PhD thesis). University of Bangor, Bangor.

Powell, F.J. and Mathews, S.L. (1987) Thermal Insulation: Materials and Systems. Issue 922. Baltimore: ASTM International, p.1.

Rockwool. (2011). Rockwool Cavity-Downloads. [Online] Available from:

http://www.rockwool.co.uk/products/building-insulation. [Accessed 04/05/14]

Rogers, H. (2005) Gone Tomorrow: The Hidden Life of Garbage. New York: The New Press, p.162.

RIBA. (2011). The Case for Space: The Size of England's New Homes. Royal Institute of British Architects: London.

Ryan, C. (2011) Traditional Construction for a Sustainable Future. Oxon: Spon Press, p.178.

Tro, N.J. (2012) Chemistry in Focus: A Molecular View of our World. $5^{\text {th }}$ ed. California: Brooks/Cole, p.375.

Vitamin D Council. (2012). Information on Vitamin D. Retrieved 12 June, 2012, from http://www.vitamindcouncil.org

Worrell, E. \& Galitsky, C. (2005) Energy Efficiency Improvement and Cost Saving Opportunities for Petroleum Refineries. (Report 56183). Ernest Orlando Lawrence.

Zach,J. Korjenic, A. Petranek, V. Hroudova, J. Bednar, T. (2012). Performance Evaluation and Research of Alternative Thermal Insulations Based on Sheep Wool. 
Energy and Buildings. Vol.49: Elsevier, pp.246-253. 